\title{
My scientific first-born
}

\author{
Robert J. Aumann
}

Published online: 20 November 2012

(C) Springer-Verlag Berlin Heidelberg 2012

\begin{abstract}
Some vignettes from the career of Professor Bezalel Peleg.
\end{abstract}
More than fifty years ago, during the academic year 1957-1958, I assisted Prof. Shmuel Agmon in an undergraduate course on the Theory of Functions of a Complex Variable, in the mathematics department of the Hebrew University in Jerusalem. Agmon gave the lectures, and I was in charge of the exercises. Every week I would assign exercises to the class - prove this, calculate that, find a counterexample to this or that. I would read the solutions that the students submitted, and give them grades ranging from 1 to 10. Most of the exercises were quite straightforward, but some were less so, and some were really difficult and challenging. In class, I would ask who had solved this or that problem, and from among the people who raised their hands, would pick one to present the solution on the blackboard.

There were three students who consistently got grades of 10 . One was the late Joram Lindenstrauss, who was to become one of the world's greatest experts in functional analysis (Banach spaces, etc.), and whose son Elon recently received the Fields medal. Another one was Micha Perles, who was to become an internationally known and admired expert in convexity and related topics; he is known to Game Theory through his papers with the late Michael Maschler on the superadditive solution to the bargaining problem (Perles and Maschler 1981), and with the writer of these lines on "A Variational Problem arising in Economics" (Aumann and Perles 1965). I would call Lindenstrauss and Perles to the blackboard fairly frequently, to present their solutions to the more challenging exercises; so I got to know their names well. But the third of the outstanding triumvirate never raised a hand, never volunteered to present a solution. I simply did not know who he was, and was very curious to know. So one

R. J. Aumann ( $)$

The Hebrew University of Jerusalem, Jerusalem, Israel

e-mail: raumann@math.huji.ac.il 
day, at the beginning of class, I simply asked, "would Mr. Bezalel Peleg please identify himself?" Bezalel raised his hand, and I said "Thank you, Mr. Peleg." That was our first encounter.

A few years later, Bezalel became my scientific first-born: the first student to do a doctorate with me. He went on to become the internationally celebrated-and prolific-Game Theorist that he is.

I close with an anecdote about our mathematics department - something that really happened. One year, the department was asked by the dean to suggest two people for slots that were opening up in the Faculty of Natural Sciences and Mathematics. Four serious mathematicians were candidates; so the department chairman, a renowned mathematician, called a department meeting to pick two out of the four. All were excellent, so the choice was difficult. After a long discussion, it was decided to take a vote. The chairman turned to me, and asked for advice on how to do this. I said that I'm no expert in voting theory; all I know is that there is no way to do it right. But if you want practical advice, I said, we do have in this room one of the world's greatest experts on voting theory, namely Prof. Bezalel Peleg. So the chairman asked Bezalel, and Bezalel suggested a method; I do not recall what it was. That method was used to select two out of the four, the meeting was closed, and we all went home.

The next morning, I met the chairman in the corridor. He said, Yisrael, your Game Theory is terrible. I said, why do you say that? He said, not only is most of the department opposed to last night's decision, but there is even a specific pair that most of the department prefers to the one chosen. I asked, which pair, so he specified it. I said, you know what, you're right; but there is another pair (which I specified) that most of the department prefers to yours, and still another pair (which I also specified) that most of the department prefers to that one, and most of the department prefers the chosen pair to that last one. Moreover, that kind of difficulty can't be avoided; it's always possible, and indeed there's a theorem to that effect. So this renowned mathematician says, "Ah, you and your theorems."

So to Bezalel I say, "Bezalel, you and your theorems: Keep it up!"

\section{References}

Aumann RJ, Perles M (1965) A variational problem arising in economics. J Math Anal Appl 11:488-503 Perles MJ, Maschler M (1981) The super-additive solution for the Nash bargaining game. Int J Game Theory 10:163-193 